\title{
Randomized Controlled Trial Of Lichtenstein Repair Of Indirect Inguinal Hernias With Two Biologic Meshes From Porcine Small Intestine Submucosa
}

Li Sun

Jie Chen

Yingmo Shen

Department of Hernia and Abdominal Wall Surgery, Beijing Chaoyang Hospital, Capital Medical University, Beijing 100043, People's Republic of China
This article was published in the following Dove Press journal:

Therapeutics and Clinical Risk Management

Background: Biologic mesh is a newly developed material for hernia repairs which has been successfully used in clinical practices. This study aims to evaluate the clinical efficacy between patients undergoing a Lichtenstein's hernioplasty with a new biologic mesh derived from porcine small intestine submucosal (SIS) extracellular matrix versus a standard SIS mesh.

Methods: A prospective, randomized, double-blinded, multi-center trial was conducted in a 6-month study. Lichtenstein hernioplasty was performed using the new SIS mesh (Beijing Biosis Healing Biotechnology) or the standard SIS mesh (Biodesign Surgisis, Cook Biotech). The postoperative follow-up examinations were carried out at during hospitalization, 1st week, 1st, 3rd, and 6th month after surgery. The primary outcome was the excellent and good rate of recovery. Secondary outcomes included recurrence rate, complications, and patientcentered outcomes.

Results: A total of 194 patients were randomized into experimental group receiving the new SIS mesh ( $n=97)$ and control group receiving the standard SIS mesh $(n=97)$. The excellent and good rate of rehabilitation in the experimental group was $98.97 \%$, while it was $100.00 \%$ in the control group $(P>0.05)$. One patient had a recurrence in the experimental group, while there was no recurrence in the control group $(P>0.05)$. Other clinical outcomes, including the length of operation or hospitalization, foreign body sensation in the inguinal area, incision healing, infection, postoperative chronic pain, postoperative allergy, hydrocele, and orchitis, were similar between the two groups.

Conclusion: Lichtenstein hernioplasty using the SIS mesh was safe and effective, and the new SIS mesh tested in this study had comparable safety and efficacy to the wildly used SIS mesh.

Keywords: hernias, lichtenstein hernioplasty, biologic mesh

\section{Introduction}

A hernia is the abnormal presence of tissue or an organ, such as the bowel, through the wall of the body cavity where it normally resides. ${ }^{1}$ Hernia is a common and frequently occurring disease, and its incidence increases with age. Adult hernia is not self-healing and must be treated early by surgery. ${ }^{2}$ Tension-free hernia repair was invented by Dr Lichtenstein and his companions at the Lichtenstein Hernia Institute in 1984. The method is to reinforce the inguinal floor with a large sheet of
Correspondence: Yingmo Shen

Department of Hernia and Abdominal

Wall Surgery, Beijing Chaoyang Hospital,

No. 5 Jingyuan Road, Shijingshan District, Beijing 100043, People's Republic of China

Tel +86-10-8888888

Fax +86-10-8888887

Email shenyingmo020I@163.com
Therapeutics and Clinical Risk Management 2019:15 1277-1282

1277

DovePress $f$ in $\boldsymbol{v}$

http://doi.org/10.2147/TCRM.S208185 
mesh, with adequate mesh tissue interface beyond the boundary of the inguinal floor and creation of a new internal ring made of prosthesis. ${ }^{3}$ Lichtenstein technique has gained worldwide popularity due to its low recurrence rate, less complications, low cost, and quick recovery after surgery. $^{4-7}$

With the rapid development of material science, various kinds of hernia repair materials have been widely used in the clinic. The hernia repair materials cover non-absorbable synthetic materials such as polypropylene, polyester, and polytetrafluoroethylene, and absorbable synthetic materials such as polylactic acid and polypropylene. ${ }^{8,9}$ After the application of artificial synthetic materials, the treatment of hernia has made great progress. However, with the prolonged application time, the problem of poorly compatible histocompatibility of non-degradable synthetic materials has become more and more prominent. In addition, if there is infection or recurrence after the implantation of synthetic mesh, it may be necessary to perform a second operation to remove the mesh, which not only increases the pain but also increases the economic burden for the patients. ${ }^{10,11}$

With the progress of biologic meshes, new alternatives are now available that avoid several shortcomings related to prosthetic meshes. Biologic meshes were advocated due to their ability to resist infection, mesh erosion into adjacent structures with resulting intestinal fistulas, or mesh migration. ${ }^{12,13}$ Various types of biologic meshes have been developed and successfully used in clinical practices. Sources for these meshes include human, porcine, and bovine materials such as dermal and submucosal intestinal tissues. The cells are removed and only the extracellular matrix is retained in these biologic materials. It is the removal of each tissue's cellular material that is believed to reduce the immunogenicity and facilitate durability and resistance to infection. ${ }^{12,13}$

The aims of this study were to evaluate the safety and efficacy of Lichtenstein's hernioplasty using a new biologic mesh from porcine small intestinal submucosal (SIS) tissues (Beijing Biosis Healing Biotechnology) for primary unilateral indirect inguinal hernia repairs, and to compare the results with a wildly used SIS mesh (Biodesign Surgisi, Cook Biotech).

\section{Materials And Methods}

\section{Patients}

Between March 2016 and October 2016, patients with unilateral primary inguinal admitted to the Department of Hernia and Abdominal Wall Surgery, in Beijing Chaoyang Hospital Affiliated to Capital Medical University, or Tianjin People Hospital, or Tianjin Medical University General Hospital were enrolled. Written informed consent was obtained from all patients before the study and this study was conducted in accordance with the Declaration of Helsinki. The study protocol was approved by the medical ethics committee of Beijing Chaoyang Hospital (No. 2015-Qi-25).

\section{Inclusion Criteria}

The inclusion criteria were: 1) 18 to 75 years of age, gender is not limited; 2) clinically diagnosed as a type II-V (Gilbert classification) unilateral primary inguinal hernia; 3) no surgical contraindications; 4) signed an informed consent, and cooperated with clinical follow-up. The type of hernia was defined as follows: type I, indirect hernia, with a small internal ring $(<1.5 \mathrm{~cm})$, and intact posterior wall of transverse fascia and inguinal canal; type II, indirect hernia, with a moderately enlarged internal ring $(1.5-3 \mathrm{~cm})$, and incomplete posterior wall of transverse fascia and inguinal canal; type III, indirect hernia, with a large internal ring $(>3 \mathrm{~cm})$, and incomplete posterior wall of transverse fascia and inguinal canal or hernia sac entering scrotum; type IV, direct hernia, with a large internal ring $(>3 \mathrm{~cm})$, and incomplete posterior wall of transverse fascia and inguinal canal; type $\mathrm{V}$, direct hernia, with a moderately enlarged internal ring $(<3 \mathrm{~cm})$, and incomplete posterior wall of transverse fascia and inguinal canal.

\section{Exclusion Criteria}

The exclusion criteria were: 1 ) could not accept the materials derived from porcine due to religious or ethnic issues; 2) participated in other clinical trials of drugs or medical devices in the past 6 months; 3) bilateral inguinal hernia, femoral hernia, incarcerated hernia, or recurrent hernia; 4) acute infection or poor control of infection of the lesion; 5) skin diseases around the surgical incision; 6) serious diseases that caused increased intra-abdominal pressure (such as severe benign prostatic hyperplasia, constipation or chronic cough; cirrhosis or uncontrolled ascites caused by tumors, etc.); 7) severe heart, liver and kidney dysfunction (heart function: grade II and above; ALT or AST $>2.5$ times of the upper limit of normal; serum creatinine $>$ upper limit of normal); 8) poor control of diabetes (continuous monitoring of fasting blood glucose $\geq 8.8 \mathrm{mmol} / \mathrm{L}$ twice); 9) serious heart, lung, brain system diseases, cancer, or AIDS; 10) specific allergic condition; 11) life expectancy less than 6 months; 12) mental disorders or lack of self-determination; 13) pregnant 
or planned pregnant women or lactating women; 14) other circumstances in which the doctor judged that patients could not participate in the trial.

\section{Sample Size Calculation}

This study was a non-inferiority study with a non-inferiority test for the main outcomes. The required sample size is calculated by the following formula:

$$
N=2 \times \pi \times(1-\pi) \times\left(\frac{U_{\alpha}+U_{\beta}}{\delta}\right)^{2}
$$

Based on the published literature and researcher's clinical practice experience, in the case of significance level of test $\alpha=0.025$ (one side), the degree of power $(1-\beta)=80 \%$, the expected excellent and good rate of the control group $\pi=0.94$, and the non-inferiority cutoff $\delta=0.10$, the required sample size was 88 cases per group. Considering the loss of follow-up rate was $10 \%, 194$ cases were planned to enroll in the study, who were equally allocated into the experimental group and the control group.

\section{Study Design}

This study was a multicenter, randomized, open, and parallel controlled clinical trial. A total of 194 enrolled patients with inguinal hernia were randomly allocated into two groups (experimental group and control group) according to the ratio of $1: 1$. Patients in the experimental group used the SIS mesh from Beijing Biosis Healing Biotechnology, while patients in the control group used the Biodesign Surgisis mesh, which has been widely used. The same group of surgeons underwent surgery at the same time according to standard Lichtenstein tension-free hernia repair procedure to compare the clinical efficacy of the two meshes. The postoperative follow-up examinations were carried out at during hospitalization, 1st week, 1st, 3rd, and 6th month after surgery.

\section{Outcome Measures}

The primary outcome was the excellent and good rate of recovery. According to the recurrence, condition of the incision, severity of postoperative pain, and other complications, the rehabilitation of the patient was graded as: excellent, good, qualified, unqualified. The grade criterion is presented in supplementary Table 1 and 2 . The secondary outcome measures included recurrence rate, length of operation or hospitalization, foreign body sensation in the inguinal area, incision healing, patch infection, postoperative chronic pain, postoperative allergy, hydrocele, and orchitis. Recurrence was evaluated by direct clinical examination, and was defined based on the findings during the follow-up period as the presence of the same type of hernia in the same inguinal region that was previously repaired. The postoperative chronic pain was assessed using a $0-10$ VAS pain score $(0=$ minimal pain, and $10=$ maximal pain).

\section{Statistical Analysis}

All statistical analyses were performed using the SPSS 19.0 software (Chicago, Illinois, USA). Continuous data were expressed as the mean $\pm \mathrm{SD}$, and the differences between two groups were examined by Student's $t$-test or Wilcoxon rank-sum test. The classification data were expressed as a percentage, and the comparison was performed using the $\chi 2$ test or Fisher's exact test. Wilcoxon rank-sum test or $\mathrm{CMH}$ test was used for rank data. $P$-values less than 0.05 were considered significant.

\section{Results}

\section{Clinical Characteristics Of Patients}

During the study period, 204 patients were diagnosed as inguinal hernias. Of these, 194 patients who met the inclusion criteria were enrolled, who were randomly divided into experiment group $(n=97)$ and control group $(n=97)$. All the patients were followed up for 6 months, and no patients were lost to follow-up. The data for all 194 patients were included for analysis, and the baseline characteristics are shown in Table 1. No significant differences in age, gender, allergy or operation history, and location or type of hernia were found between the experiment group and control group. The majority of hernias type was type 2 $(n=110,56.7 \%)$.

\section{Clinical Outcomes}

The primary outcome compared the excellent and good rate of recovery in the two groups of patients in 6 months of follow-up. The excellent and good rate in the control group was $100.00 \%$, while it was $98.97 \%$ in the experimental group (Table 2). There was no significant difference in the excellent and good rate of recovery between the two groups $(P=0.312)$. Secondary outcome measures included recurrence, length of operation or hospitalization, foreign body sensation in the inguinal area, incision healing, infection, postoperative chronic pain, postoperative allergy, hydrocele, and orchitis. There were no significant differences between the two groups in these indicators 
Table I Baseline Characteristics Of The Patients

\begin{tabular}{|c|c|c|c|}
\hline & $\begin{array}{l}\text { Experimental } \\
\text { Group }\end{array}$ & $\begin{array}{l}\text { Control } \\
\text { Group }\end{array}$ & P-value \\
\hline & $(n=97)$ & $(n=97)$ & \\
\hline Age (years) & $46.12 \pm 16.02$ & $48.65 \pm 15.48$ & $0.28 \mathrm{I}$ \\
\hline Gender & & & 0.339 \\
\hline Male & 83 (85.57\%) & 78 (80.4l\%) & \\
\hline Female & 14 (I4.43\%) & 19 (19.59\%) & \\
\hline Allergic history & 10 (10.31\%) & $5(5.15 \%)$ & 0.179 \\
\hline Operation history & $26(32.10 \%)$ & $23(28.40 \%)$ & 0.608 \\
\hline Location of hernia & & & 0.304 \\
\hline Left & 35 (36.08\%) & $42(43.30 \%)$ & \\
\hline Right & 62 (63.92\%) & 55 (56.70\%) & \\
\hline Hernia type & & & 0.901 \\
\hline II & 56 (57.73\%) & $54(55.67 \%)$ & \\
\hline III & 31 (31.96\%) & 30 (30.93\%) & \\
\hline IV & $4(4.12 \%)$ & $4(4.12 \%)$ & \\
\hline V & $6(6.19 \%)$ & 9 (9.28\%) & \\
\hline
\end{tabular}

(Tables 2 and 3). In detail, there was no recurrence in the control group, while one patient had a recurrence in the experimental group at the 6-month follow-up. The length of operation was $50.01 \pm 13.04$ mins in the experimental group, while it was $50.27 \pm 13.38$ mins in the control group. The length of hospitalization was $1.94 \pm 0.90$ days in the experimental group, while it was $1.80 \pm 0.81$ days in the control group. In the experimental group, there were 2 cases of obvious foreign body sensation during the hospitalization, and 4 cases at the 1st week after operation, but there were no such cases at other time periods. In the control group, there were 3, 9, and 2 cases of obvious foreign body sensation in hospitalization period, 1stweek after operation, and 1 st month after operation, respectively, but there were no such cases at other time periods. Four and 2 cases developed incision redness and swelling in 1st week and 1st month after operation in the experimental group, while 2 and 1 cases developed incision redness and swelling in 1st week and 1st month after operation in the control group. There was 1 case of incision hematoma or seroma at 6 months after operation in the experimental group, while there were 3 cases of incision hematoma or seroma at the 1st week after operation in the control group. There were no mesh infections, allergies, hydrocele, and orchitis in both two groups during the follow-up period. One patient in the experimental group had a postoperative VAS pain score of 4-6 points, and all others were $\leq 3$ points
Table 2 Major Clinical Outcomes

\begin{tabular}{|c|c|c|c|}
\hline \multirow[t]{2}{*}{ Clinical Outcome } & $\begin{array}{l}\text { Experimental } \\
\text { Group }\end{array}$ & $\begin{array}{l}\text { Control } \\
\text { Group }\end{array}$ & \multirow[t]{2}{*}{ P-value } \\
\hline & $(n=97)$ & $(n=97)$ & \\
\hline $\begin{array}{l}\text { Excellent and good } \\
\text { rate* }\end{array}$ & 96 (98.97\%) & $\begin{array}{l}97 \\
(100.00 \%)\end{array}$ & 0.312 \\
\hline Recurrence rate* & I (1.03\%) & $0(0.00 \%)$ & 0.312 \\
\hline $\begin{array}{l}\text { Length of operation } \\
\text { (min) }\end{array}$ & $50.01 \pm 13.04$ & $\begin{array}{l}50.27 \\
\pm 13.38\end{array}$ & 0.748 \\
\hline $\begin{array}{l}\text { Length of } \\
\text { hospitalization (d) }\end{array}$ & $1.94 \pm 0.90$ & $1.80 \pm 0.81$ & 0.271 \\
\hline Incidence of hydrocele* & $0(0.00 \%)$ & $0(0.00 \%)$ & - \\
\hline Incidence of allergy* & $0(0.00 \%)$ & $0(0.00 \%)$ & - \\
\hline Incidence of orchitis* & $0(0.00 \%)$ & $0(0.00 \%)$ & - \\
\hline Incidence of infection* & $0(0.00 \%)$ & $0(0.00 \%)$ & - \\
\hline Foreign body sensation & & & \\
\hline During hospitalisation & $2(2.06 \%)$ & $3(3.09 \%)$ & 0.651 \\
\hline Week I & $4(4.12 \%)$ & 9 (9.28\%) & 0.152 \\
\hline Month I & $0(0.00 \%)$ & $2(2.06 \%)$ & 0.156 \\
\hline Month 3 & $0(0.00 \%)$ & $0(0.00 \%)$ & - \\
\hline Month 6 & $0(0.00 \%)$ & $0(0.00 \%)$ & - \\
\hline \multicolumn{4}{|l|}{$\begin{array}{l}\text { Incision redness and } \\
\text { swelling }\end{array}$} \\
\hline During hospitalisation & $0(0.00 \%)$ & $0(0.00 \%)$ & - \\
\hline Week I & $4(4.12 \%)$ & $2(2.06 \%)$ & 0.408 \\
\hline Month I & $2(2.06 \%)$ & I (I.03\%) & 0.562 \\
\hline Month 3 & $0(0.00 \%)$ & $0(0.00 \%)$ & - \\
\hline Month 6 & $0(0.00 \%)$ & $0(0.00 \%)$ & - \\
\hline \multicolumn{4}{|l|}{$\begin{array}{l}\text { Incision hematoma or } \\
\text { seroma }\end{array}$} \\
\hline During hospitalisation & $0(0.00 \%)$ & $0(0.00 \%)$ & - \\
\hline Week I & $0(0.00 \%)$ & $3(3.09 \%)$ & 0.082 \\
\hline Month I & $0(0.00 \%)$ & $0(0.00 \%)$ & - \\
\hline Month 3 & $0(0.00 \%)$ & 0 (0.00\%) & - \\
\hline Month 6 & I (0.00\%) & 0 (0.00\%) & 0.317 \\
\hline
\end{tabular}

Note: *Recorded within 6 months after the operation.

during the hospitalization period. All subjects at all other time periods scored $\leq 3$ points. In the control group, the pain scores of two subjects were 4-6 points, and other subjects were $\leq 3$ points during the hospitalization period. At the 1st week after surgery, 1 subject scored 4-6 points, 1 case was $7-10$ points, and other subjects were $\leq 3$ points. At other times, all subjects were rated $\leq 3$ points.

\section{Discussion}

Hernia repair has evolved from suture repair to mesh repair over the last three decades. Various prosthetic meshes are currently available for use in different types 
Table 3 Pain Scores In Patients After Hernia Repair

\begin{tabular}{|c|c|c|c|}
\hline \multirow[t]{2}{*}{ Pain Scores* } & $\begin{array}{l}\text { Experimental } \\
\text { Group }\end{array}$ & $\begin{array}{l}\text { Control } \\
\text { Group }\end{array}$ & P-value \\
\hline & $(n=97)$ & $(n=97)$ & \\
\hline $\begin{array}{l}\text { During hospitalisation } \\
\qquad 3 \\
4-6 \\
7-10\end{array}$ & $\begin{array}{l}96(98.97 \%) \\
\text { I (1.03\%) } \\
0(0.00 \%)\end{array}$ & $\begin{array}{l}95(97.94 \%) \\
2(2.06 \%) \\
0(0.00 \%)\end{array}$ & 0.562 \\
\hline $\begin{array}{l}\text { Week I } \\
\leq 3 \\
4-6 \\
7-10\end{array}$ & $\begin{array}{l}97(100.00 \%) \\
0(0.00 \%) \\
0(0.00 \%)\end{array}$ & $\begin{array}{l}95(97.94 \%) \\
\text { I (I.03\%) } \\
\text { I (I.03\%) }\end{array}$ & 0.179 \\
\hline $\begin{array}{l}\text { Month I } \\
\leq 3 \\
4-6 \\
7-10\end{array}$ & $\begin{array}{l}97(100.00 \%) \\
0(0.00 \%) \\
0(0.00 \%)\end{array}$ & $\begin{array}{l}97(100.00 \%) \\
0(0.00 \%) \\
0(0.00 \%)\end{array}$ & - \\
\hline $\begin{array}{l}\text { Month } 3 \\
\leq 3 \\
4-6 \\
7-10\end{array}$ & $\begin{array}{l}97(100.00 \%) \\
0(0.00 \%) \\
0(0.00 \%)\end{array}$ & $\begin{array}{l}97(100.00 \%) \\
0(0.00 \%) \\
0(0.00 \%)\end{array}$ & - \\
\hline $\begin{array}{c}\text { Month } 6 \\
\leq 3 \\
4-6 \\
7-10\end{array}$ & $\begin{array}{l}97(100.00 \%) \\
0(0.00 \%) \\
0(0.00 \%)\end{array}$ & $\begin{array}{l}97(100.00 \%) \\
0(0.00 \%) \\
0(0.00 \%)\end{array}$ & - \\
\hline
\end{tabular}

Notes: $* 0=$ no pain, $10=$ unbearable pain.

of surgery, which may be either synthetic or biologic. Synthetic meshes have been used for a long time, and their clinical efficacy has been validated in numerous cases. However, long-term follow-up studies also have revealed several concerning complications with synthetic meshes, including mesh erosion into the bowel resulting in fistula formation, bowel obstruction, mesh infection, and need for eventual mesh removal. ${ }^{9}$ Biologic meshes have been introduced since the 1990s, which can be derived from human (allograft) or animal (xenograft: porcine or bovine) tissues. The best studied biologic meshes are the ones derived from dermal and submucosal intestinal tissues. ${ }^{12,13}$ The meshes used in this study derived from porcine SIS tissues, which have removed immunogenicity, and has good biocompatibility, mechanical strength, suitable porosity, and degradability. Biologic meshes allow neovascularization and regeneration because of infiltration of native fibroblasts, which provide the extracellular scaffold necessary for the reconstruction of healthy tissue. ${ }^{14,15}$ On the other hand, biologic meshes are relatively expensive. Because of added complexities, biologic graft implantation might require added technical expertise, resulting in longer operating time. It was also reported that biologic grafts caused higher incidence of seroma. ${ }^{16}$

Biologic grafts are recommended to use for abdominal wall reinforcement in infected fields. To date, no consensus has been reached on their use for inguinal hernia repairing. ${ }^{17}$ However, increasing evidence has proved that biologic meshes are safe and effective in inguinal hernia repairs, at least with comparable clinical outcome to the synthetic mesh. Bellows et al reported that Strattice ${ }^{\mathrm{TM}}$, a biologic mesh derived from porcine dermis, is safe and effective in repairing inguinal hernia, with comparable intra-operative and early postoperative morbidity to Ultrapro, a lightweight synthetic mesh. ${ }^{18}$ Bochicchio et al found that inguinal hernia repair with Surgisis mesh, a porcine SIS mesh, compares favorably with polypropylene mesh with similar recurrence rates and complications. ${ }^{19}$ The clinical efficacy of Surgisis mesh is also validated by other two studies. ${ }^{20,21}$

In this study, using a standard randomized controlled trial, we confirm that Lichtenstein hernioplasty using the SIS mesh has a high safety and efficacy. We compared the clinical efficacy of a new SIS mesh with a standard SIS mesh (Surgisis). The major clinical outcomes, including the recurrence rate, length of operation or hospitalization, foreign body sensation in the inguinal area, incision healing, infection, postoperative chronic pain, postoperative allergy, hydrocele, and orchitis, are similar between two groups. The design of this study is different from the previous clinical trial design. Instead of simply comparing the changes of clinical observation outcomes before and after surgery, the outcomes are combined to calculate the excellent and good rate of each group by a unified and weighting method. A comprehensive evaluation of the clinical efficacy of the experimental group and the control group was made by comparing the excellent and good rate. In this study, the excellent and good rates were high in both groups, and the short-term efficacy was satisfactory, but the long-term efficacy still needs further observation.

\section{Disclosure}

The authors declare no competing interests in this work.

\section{References}

1. Fitzgibbons RJ Jr, Forse RA. Clinical practice. Groin hernias in adults. $N$ Engl J Med. 2015;372:756-763. doi:10.1056/NEJMcp1404068

2. HerniaSurge Group. International guidelines for groin hernia management. Hernia. 2018;22:1-165. 
3. Amid PK, Lichtenstein IL. Long-term result and current status of the lichtenstein open tension-free hernioplasty. Hernia. 1998;2:89-94. doi:10.1007/BF01207492

4. Amid PK. Lichtenstein tension-free hernioplasty: its inception, evolution, and principles. Hernia. 2004;8:1-7. doi:10.1007/s10029-003-0160-y

5. Porrero JL, Castillo MJ, Pérez-Zapata A, et al. Randomised clinical trial: conventional lichtenstein vs. hernioplasty with self-adhesive mesh in bilateral inguinal hernia surgery. Hernia. 2015;19:765-770. doi:10.1007/s10029-014-1316-7

6. Hoyuela C, Juvany M, Carvajal F, et al. Randomized clinical trial of mesh fixation with glue or sutures for lichtenstein hernia repair. $\mathrm{Br} J$ Surg. 2017;104:688-694. doi:10.1002/bjs.10488

7. Yang J, Tong da N, Yao J, Chen W. Laparoscopic or lichtenstein repair for recurrent inguinal hernia: a meta-analysis of randomized controlled trials. ANZ J Surg. 2013;83:312-318. doi:10.1111/ans.12010

8. Bachman S, Ramshaw B. Prosthetic material in ventral hernia repair: how do I choose? Surg Clin North Am. 2008;88:101-112. doi:10.1016/j.suc.2007.11.001

9. Robinson TN, Clarke JH, Schoen J, Walsh MD. Major mesh-related complications following hernia repair: events reported to the Food and Drug Administration. Surg Endosc. 2005;19:1556-15560. doi:10.1007/s00464-005-0120-y

10. Cobb WS, Kercher KW, Heniford BT. The argument for lightweight polypropylene mesh in hernia repair. Surg Innov. 2005;12:63-69. doi: $10.1177 / 155335060501200109$

11. Kobashi KC, Govier FE. Management of vaginal erosion of polypropylene mesh slings. J Urol. 2003;169:2242-2243. doi:10.1097/01. ju.0000060119.43064.f6

12. Smart NJ, Marshall M, Daniels IR. Biological meshes: a review of their use in abdominal wall hernia repairs. Surgeon. 2012;10:159171. doi:10.1016/j.surge.2012.02.006

13. Kissane NA, Itani KM. A decade of ventral incisional hernia repairs with biologic acellular dermal matrix: what have we learned? Plast Reconstr Surg. 2012;130:194-202. doi:10.1097/PRS.0b013e318265a5ec
14. Deeken CR, Melman L, Jenkins ED, et al. Histologic and biomechanical evaluation of crosslinked and non-crosslinked biologic meshes in a porcine model of ventral incisional hernia repair. $J$ Am Coll Surg. 2011;212:880-888. doi:10.1016/j.jamcollsurg.2011. 01.006

15. Majumder A, Winder JS, Wen Y, Pauli EM, Belyansky I, Novitsky YW. Comparative analysis of biologic versus synthetic mesh outcomes in contaminated hernia repairs. Surgery. 2016;160:828-838. doi:10.1016/j.surg.2016.04.041

16. Fang Z, Ren F, Zhou J, Tian J. Biologic mesh versus synthetic mesh in open inguinal hernia repair: system review and meta-analysis. $A N Z$ J Surg. 2015;85:910-916. doi:10.1111/ans.13234

17. El-Hayek KM, Chand B. Biologic prosthetic materials for hernia repairs. J Long Term Eff Med Implants. 2010;20:159-169.

18. Bellows CF, Shadduck P, Helton WS, Martindale R, Stouch BC, Fitzgibbons R. Early report of a randomized comparative clinical trial of strattice reconstructive tissue matrix to lightweight synthetic mesh in the repair of inguinal hernias. Hernia. 2014;18:221-230. doi:10.1007/s10029-013-1076-9

19. Bochicchio GV, Jain A, McGonigal K, et al. Biologic vs synthetic inguinal hernia repair: 1-year results of a randomized double-blinded trial. J Am Coll Surg. 2014;218:751-757. doi:10.1016/j. jamcollsurg.2014.01.043

20. Puccio F, Solazzo M, Marciano P. Comparison of three different mesh materials in tension-free inguinal hernia repair: prolene versus vypro versus surgisis. Int Surg. 2005;90:S21-23.

21. Ansaloni L, Catena F, Coccolini F, Gazzotti F, D’Alessandro L, Pinna AD. Inguinal hernia repair with porcine small intestine submucosa: 3year follow-up results of a randomized controlled trial of lichtenstein's repair with polypropylene mesh versus surgisis inguinal hernia matrix. Am J Surg. 2009;198:303-312. doi:10.1016/j.amjsurg.2008.09.021
Therapeutics and Clinical Risk Management

\section{Publish your work in this journal}

Therapeutics and Clinical Risk Management is an international, peerreviewed journal of clinical therapeutics and risk management, focusing on concise rapid reporting of clinical studies in all therapeutic areas, outcomes, safety, and programs for the effective, safe, and sustained use of medicines. This journal is indexed on PubMed Central, CAS,

\section{Dovepress}

EMBase, Scopus and the Elsevier Bibliographic databases. The manuscript management system is completely online and includes a very quick and fair peer-review system, which is all easy to use. Visit http://www.dovepress.com/testimonials.php to read real quotes from published authors. 